\title{
Nota Científica \\ Aspectos ecológicos de Byrsonima intermedia em microambientes ripários
}

\author{
Allan de Freitas Magalhães ${ }^{1}$, Dulcinéia de Carvalho ${ }^{1}$, Jessé Marques da Silva Júnior ${ }^{1}$, João Carlos Costa Guimarães ${ }^{1}$
}

${ }^{1}$ Universidade Federal de Lavras, Departamento de Ciências Florestais, CEP 37.200-000, Lavras, MG, Brasil

\author{
*Autor correspondente: \\ allanfmbh@yahoo.com.br \\ Termos para indexação: \\ Diásporo \\ Embebição \\ Germinação \\ Inundação \\ Plântula \\ Index terms: \\ Diaspore \\ Imbibition \\ Germination \\ Flooding \\ Seedling
}

Histórico do artigo:

Recebido em 07/12/2012

Aprovado em 25/11/2013

Publicado em 31/12/2013

doi: 10.4336/2013.pfb.33.76.463

\begin{abstract}
Resumo - Objetivou conhecer a ecologia de Byrsonima intermedia A. Juss. e os mecanismos de estabelecimento inicial dessa espécie em microambientes ripários. O trabalho foi realizado na Estação Ambiental Peti - PETI (1953'34,1”; $43^{\circ} 21^{\prime} 52,6$ "), São Gonçalo do Rio Abaixo, MG. Os parâmetros ecológicos estudados foram: umidade durante a dispersão (fruto, diásporo e sementes) e após dispersão (embebição; crescimento e desenvolvimento inicial). Diásporos e sementes apresentam comportamentos distintos, sendo o processo de absorção de água mais acelerado em sementes com ausência de endocarpo. A duração total de crescimento do embrião até o estágio de plântula foi de 21 dias. Plântulas desenvolvem-se preferencialmente em ambientes inundados.
\end{abstract}

\section{Ecological aspects of Byrsonima intermedia in riparian microenvironments}

\begin{abstract}
This work aimed to better understand the ecology of Byrsonima intermedia A. Juss. and the mechanisms for initial establishment of this species in riparian microenvironments. The study was conducted at Peti Environmental Station - PETI (1953'34.1"; 43²1'52.6"), São Gonçalo do Rio Abaixo, Minas Gerais State, Brazil. The ecological parameters studied were: moisture at dispersion (fruit, seed and diaspore) and after dispersion (imbibition; initial growth and development). Diaspores and seeds present different behaviors. The faster water absorption process was in seeds without endocarp. The total growth length from embryo until seedling was 21 days. Seedlings establishes preferentially in flooded environments.
\end{abstract}

Espécies vegetais pertencentes ao gênero Byrsonima Rich. Ex. Kunth. são caracterizadas por alta plasticidade fenotípica, com ampla ocorrência nas diversas composições florística da América do Sul (Mamede, 2011). O gênero não é exclusivo de fitofisionomias fechadas, ocorrendo alguns deles em ambiente de cerrado, nos Estados de Mato Grosso e Goiás e no litoral norte e nordeste do país (Anderson, 1977). Suas flores coloridas possuem glândulas de óleo na base, atraindo diversas espécies de fauna, em especial a entomofauna (Sigrist \& Sazima, 2004). Byrsonima intermedia A. Juss. (Malpighiaceae) é uma espécie com ocorrência em ambientes xéricos e áreas úmidas, como as florestas ripárias. Poucos estudos relatam a ecologia da espécie em áreas ripárias, não havendo trabalhos com caracterização morfológica de sementes e plântulas. As árvores podem atingir de 4 a 6 metros de altura e os estudos sobre a sua biologia reprodutiva enfocam o comportamento e ação das abelhas (Vilas-Boas, 2009) e formigas (Réu Júnior, 2005) na polinização. Considerando a alta degradação de áreas ripárias e a importância da sua utilização para a restauração destas áreas, estudos abordando a morfologia 
e a ecologia dos seus mecanismos de dispersão podem elucidar as estratégias de crescimento, desenvolvimento e sobrevivência nestes ambientes (Darosci \& Paulilo, 2011). Neste sentido, o presente trabalho objetivou descrever a ecologia da espécie $B$. intermedia, visando elucidar o comportamento inicial de crescimento e desenvolvimento de espécies arbóreas em ambientes ripários.

O estudo foi conduzido na Estação Ambiental de Peti (1953'34,1" S; 43²1'52,6” O), em São Gonçalo do Rio Abaixo, MG. Foram definidos dois microambientes próximos à margem da floresta ripária em função da luminosidade e do nível da água decorrente de eventos de inundação, frequentes entre maio e setembro, quando adentra a vegetação florestal (Mallik et al., 2001).

Estruturas propagativas foram coletadas aleatoriamente em quatro posições na copa das árvores. Em cada matriz foram coletados aproximadamente 300 frutos, com o mínimo de 12 matrizes por microambiente (Davide \& Silva, 2008).

Nas estruturas (fruto, diásporo e semente) foi realizado teste de umidade para determinação do conteúdo inicial de água e embebição em água destilada (Brasil, 2009). Foram utilizadas 50 sementes e 50 diásporos (endocarpo + semente) para ambos os microambientes. Nos diásporos foi avaliado o intervalo de tempo para o aparecimento da semente, pelo rompimento do endocarpo. As estruturas propagativas foram incubadas em câmara de germinação do tipo BOD, a $25^{\circ} \mathrm{C}$ e luz contínua.

Visitas à campo foram realizadas para a observação de possíveis formas de estabelecimento da espécie nestes ambientes. As observações foram realizadas eventualmente nas margens do lago e no interior da vegetação, próximo às matrizes. Nestes locais, foram amostrados 15 indivíduos aleatoriamente para posterior caracterização e descrição.

Após a retirada do endocarpo, foi realizado teste de germinação das sementes de $B$. intermedia utilizandose 200 unidades (4 repetições de 50 sementes) em papel de germinação umedecido com água destilada acondicionado em placa de petri, a $25^{\circ} \mathrm{C}$ e luz contínua, durante 30 dias, para avaliação do desenvolvimento embrionário e definição do tempo requerido para formação de plântula normal. A partir deste material, foram obtidas imagens dos estágios de desenvolvimento do embrião, utilizando estereomicroscópio com máquina fotográfica acoplada. Após o estágio final de desenvolvimento das plântulas, alguns indivíduos foram selecionados e avaliados individualmente quanto a sua morfometria, conforme Nakagawa (1999).
A umidade inicial dos frutos de $B$. intermedia não variou significativamente em função dos microambientes. Entretanto, houve uma alteração de acordo com o seu compartimento interno, sendo que os valores de umidade variou entre $5 \%$ e $10 \%$, a polpa do fruto contribuiu com um valor aproximado de $59 \%$ e o diásporo apresentou valores medianos, entre $27 \%$ e $32 \%$ (Figura 1).

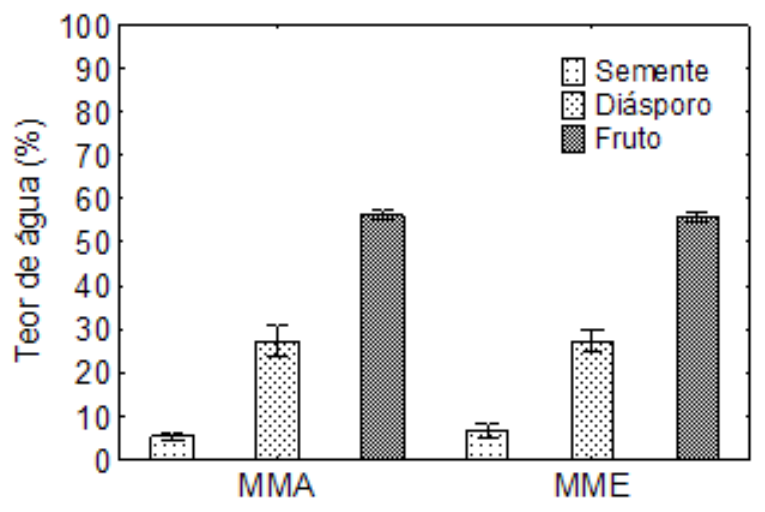

Figura 1. Teor de água em estruturas propagativas de Byrsonima intermedia nos microambientes margem (MMA) e meio (MME), na Bacia do Rio Doce, $\mathrm{MG}$.

Em relação ao padrão de absorção de água, a taxa de embebição mostrou que não há impedimento da absorção de água pelos diásporos e sementes, porém os comportamentos foram distintos, sendo mais rápido para as sementes (Figura 2). Para ambas as estruturas, a fase inicial de absorção de água (fase I), durou aproximadamente $10 \mathrm{~h}$, com ganho de $60 \%$ da capacidade total. Esta fase também foi caracterizada pelo rompimento de estrutura do diásporo pela semente.

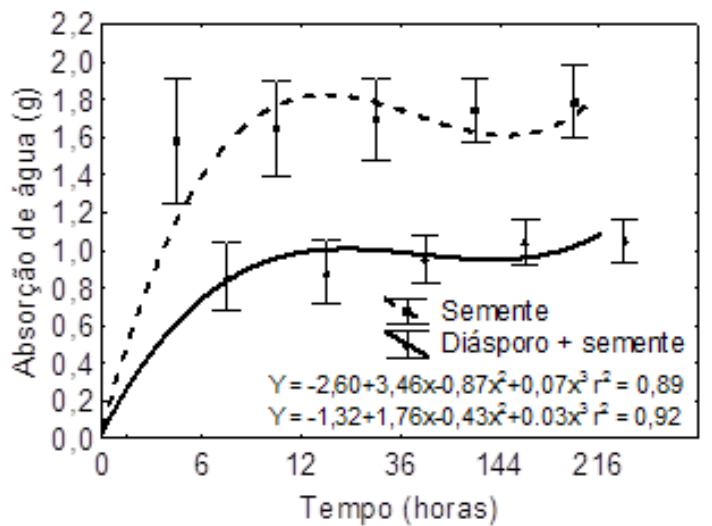

Figura 2. Curva de absorção de água da semente e do diásporo de Byrsonima intermedia. 
A segunda fase da embebição (fase II), com intervalo de duração entre 10 h e 144 h, constitui o período mais longo e estável, ocorrendo uma menor absorção de água neste período em ambas as estruturas (Figura 3). $\mathrm{Na}$ última fase de embebição (fase III), após cerca de 144 h, ainda que inicialmente, ocorreu a protrusão da raiz. Isto é caracterizado pelo rompimento das camadas internas devido a sua estrutura estar mais frágil, comparado às camadas externas. Em relação à germinação, poucas sementes (15 unidades) apresentaram protrusão da raiz, devido à presença de dormência fisiológica, caracterizada pela ausência de diferenciação nos tecidos, com consequente inativação da protrusão radicular.

Uma descrição sobre a ecologia desta espécie referese à ocorrência de banco de plântulas somente no microambiente MMA. Todas as plântulas apresentaram estruturas: folha cotiledonar, epicótilo, hipocótilo, raiz primária e secundária. As raízes se encontravam parcialmente fixadas nos sedimentos e, as folhas se aproximavam da superfície da água (Figuras 3A e 3B).

Plântulas de $B$. intermedia possuem folhas cotiledonares apresentando média de 17,64 $\pm 2,65 \mathrm{~mm}$, com largura média de 3,24 $\pm 0,46 \mathrm{~mm}$. O hipocótilo apresentou o comprimento médio de 16,22 $\pm 4,19 \mathrm{~mm}$ e largura de $0,90 \pm 0,19 \mathrm{~mm}$, com a raiz primária apresentando grande variação no comprimento, atingindo média de 9,70 $\pm 6,34 \mathrm{~mm}$, e espessura de $0,68 \pm 0,08 \mathrm{~mm}$. Esta grande variação do comprimento da raiz primária ocorreu devido à má formação do sistema radicular em testes de germinação no laboratório.

O diásporo possui superfície rugosa e alta resistência mecânica (Figura 4A). Possui três cavidades e o número de sementes varia de uma a três (Figura 4B). O embrião da semente possui formato enovelado, com coloração branca, sendo constituído por cotilédone, hipocótilo e radícula (Figura 4C). O embrião é envolvido por um tegumento fino de coloração marrom (Figura 4D) (Barroso et al., 1999). O rompimento do pirênio ocorreu com nove dias de incubação - caracterizado pelo rompimento do endocarpo pela raiz primária e crescimento do epicótilo (Figura 4E) com o início do estiramento das folhas cotiledonares e a pigmentação de seus tecidos, normalmente com duração máxima de três dias (Figura 4F). Após 15 dias a plântula iniciou a expansão dos cotilédones (Figura 4G). A penúltima fase foi caracterizada pelo enrijecimento dos cotilédones e do epicótilo. No último estágio iniciou-se o prolongamento da radícula e surgimento dos protófilos (Figura 4H). O período total de crescimento teve duração média de 21 dias.

Os teores de água determinados para os diferentes compartimentos da estrutura propagativa em $B$. intermedia mostraram que as sementes possuem conteúdo hídrico muito inferior comparado aos demais compartimentos (diásporo e polpa do fruto). Os diferentes graus de hidratação entre as partes da estrutura propagativas podem ser atribuídos às diferenças na composição química, à morfologia das partes e às variações na permeabilidade dos tecidos (International Seed Testing Association, 1993). O teor de água de um óvulo recém-fecundado é de no mínimo $80 \%$, e vai diminuindo à medida que a semente se desenvolve (Marcos Filho, 2005). Esse decréscimo do grau de umidade depende das características da espécie (Fenner \& Thompson, 2005).

$B$. intermedia apresentou alta umidade da drupa dos frutos (59\%), o que possivelmente está associado ao potencial da espécie ser atrativa a insetos e microorganismos, justificando sua dispersão por zoocoria (Garcia-Nunes et al., 2001).
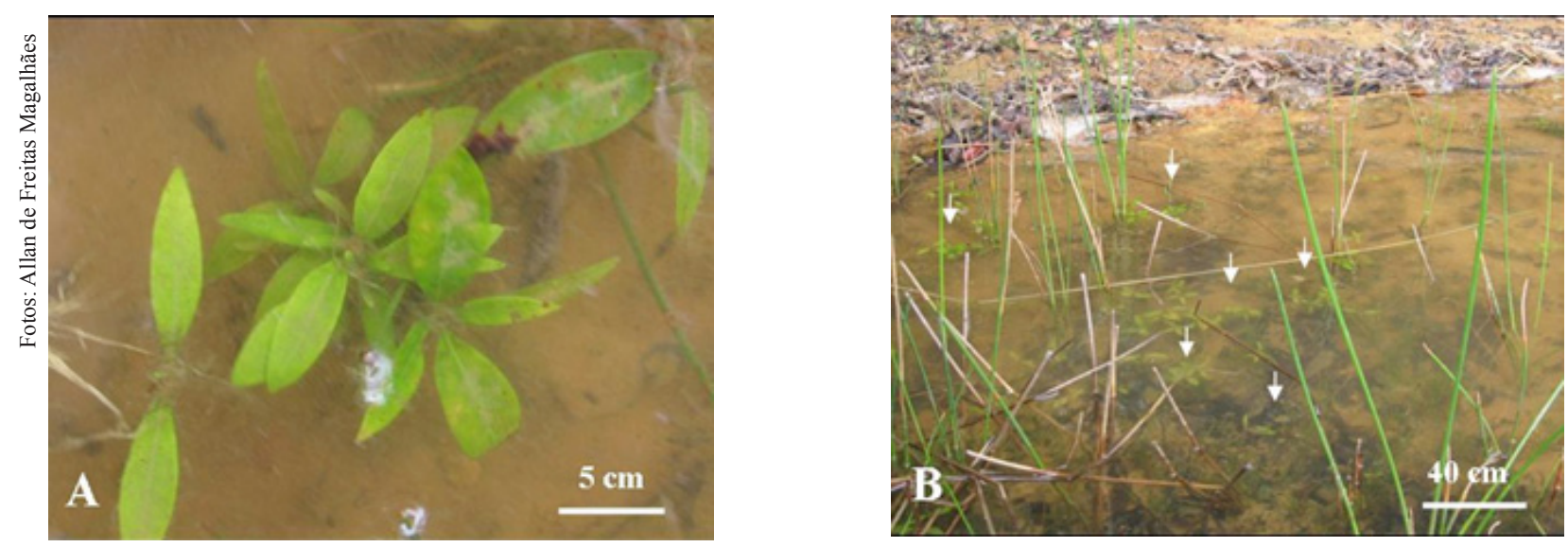

Figura 4. Indivíduo de $B$. intermedia crescendo em ambiente alagado (A). Aglomerado de plantas de $B$. intermedia presentes em área alagada próxima à margem. As setas indicam os indivíduos de $B$. intermedia presentes na área alagada (B). 


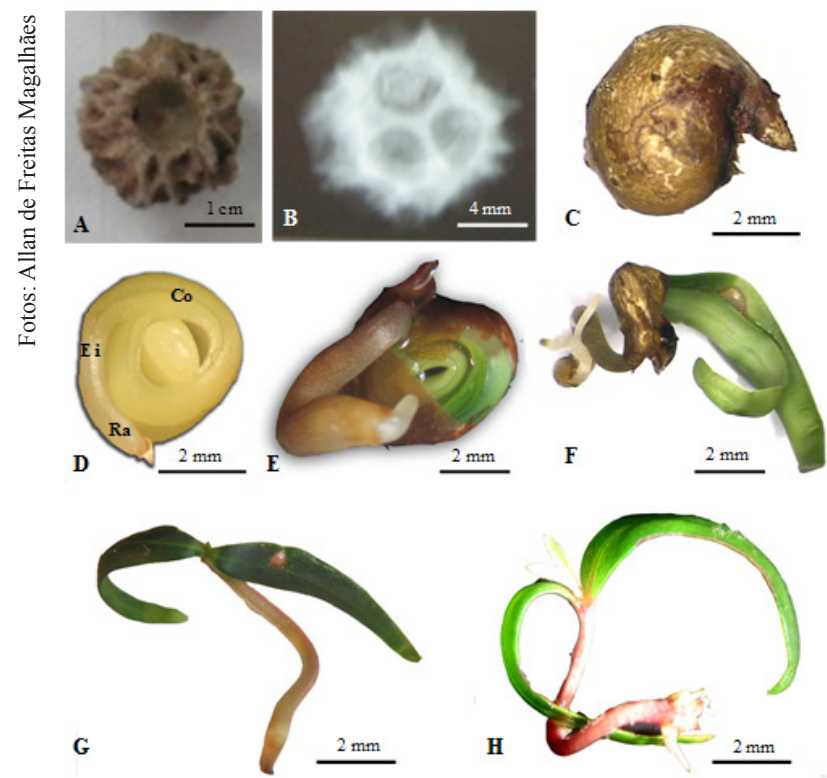

Figura 5. Imagens da espécie $B$. intermedia: diásporo (A); radiografia do diásporo mostrando os três locus com sementes (B); semente (C); embrião (D); semente germinada (E); plântula em desenvolvimento inicial $(\mathrm{F})$; plântula anormal $(\mathrm{G})$; e plântula $(\mathrm{H})$. $(\mathrm{Co}=$ cotilédone, $\mathrm{Ei}=$ eixo hipocótilo radícula, $\mathrm{Ra}=$ radícula).

A Fase I da embebição de $B$. intermedia é caracterizada pela rápida transferência de água do substrato para a semente, devido à diferença acentuada entre os potenciais osmóticos. Na Fase II, a velocidade de hidratação e intensidade de respiração das sementes da espécie estudada diminuiu drasticamente. Esta fase, caracterizada por atividades constituintes do processo bioquímico, é necessária para a síntese de enzimas, de DNA e de mRNA, exauridos na Fase I. O início da Fase III é concretizado pela retomada de crescimento do embrião, identificado pela protrusão da raiz primária (Marcos Filho, 2005).

Os diásporos de $B$. intermedia possuem densidade superior à densidade da água e não conseguem ser transportados pela água. Além disso, no segundo estágio de crescimento, a semente da espécie desenvolve um epicótilo alongado, permitindo sua fixação, juntamente com o crescimento da raiz primária, em sedimentos próximos do corpo d'água. O período total de germinação de 21 dias permite a classificação de $B$. intermedia como planta de ambiente ripário. Portanto, a sua rapidez de germinação e conformação são apropriadas para a espécie se estabelecer em ambientes inundados (Rodrigues \& Shepherd, 2000).
Araújo et al. (2004) observou a importância do banco de plântulas na manutenção de ecossistemas vegetais ripários comparado à efetividade das chuvas e do banco de sementes. Desta maneira, estas unidades funcionais exercem seu importante papel na disseminação da espécie em ambientes ripários, especificamente os inundados. Estudos similares com outras espécies típicas de microambientes ripários inundáveis são fundamentais para revelar as estratégias ecológicas, permitindo um melhor entendimento sobre o respectivo manejo e conservação.

\section{Conclusões}

Sementes de Byrsonima intermedia apresentaram comportamento distinto quanto à velocidade de absorção de água em diásporos, embebendo um volume maior para um mesmo tempo. Possivelmente, as plântulas apresentam desenvolvimento preferencial em ambiente inundado sujeito a cheias periódicas. O tempo médio para o crescimento total do embrião até o estágio de plântula foi de 21 dias, sendo que o sistema radicular apresentou boa adaptação para o estabelecimento da plântula nas áreas sujeitas a inundações.

\section{Agradecimentos}

À FAPEMIG pelo suporte financeiro e à empresa CEMIG pela disponibilização da área de coleta.

\section{Referências}

ANDERSON, W. R. Byrsonimoideae, a new subfamily of the Malpighiaceae. Revista Leandra, Rio de Janeiro, v. 7, p. 5-18, 1977.

ARAÚJO, M. M.; LONGHI, S. J.; BARROS, P. L. C.; BRENA, D. A. Caracterização da chuva de sementes, banco de sementes no solo e banco de plântulas em floresta estacional decidual ripária Cachoeira do Sul, RS, Brasil. Scientia Forestalis, Piracicaba, v. 66, p. 128-141, 2004.

BARROSO, G. M.; MORIM, M. P.; PEIXOTO, A. L.; ICHASO, C. L. F. Frutos e sementes: morfologia aplicada à sistemática de dicotiledôneas. Viçosa, MG: UFV, 1999. 443 p.

BRASIL. Ministério da Agricultura, Pecuária e Abastecimento. Secretaria de Defesa Agropecuária. Regras para análise de sementes. Brasília, DF, 2009. 399 p.

DAROSCI, A. A.; PAULILO, M. T. S. Ecophysiological aspects of the seed and seedling of Raulinoa echinata (Rutaceae), a species endemic to the riparian forests of Itajaí valley, SC, Brazil. Rodriguésia, Rio de Janeiro, v. 62, n. 2, p. 273-281, 2011. 
DAVIDE, A. C.; SILVA, E. A. A. Produção de sementes e mudas de espécies florestais. Lavras: Ed. UFLA, 2008. 175 p.

FENNER M.; THOMPSON, K. The ecology of seeds. Cambridge, U.K.: Cambridge University Press, 2005. 250 p.

GARCIA-NUNES, C.; AZOCAR, A.; SILVA, J. F. Seed production and soil seed bank in three evergreen woody species from a neotropical savanna. Journal of Tropical Ecology, Cambridge, U.K., v. 17, n. 4, p. 563-576, 2001.

INTERNATIONAL SEED TESTINGASSOCIATION. International rules for seed testing. Zurique, Suíça, 1993. 288 p.

MALLIK, A. U.; LAMB, E. G.; RASID, H. Vegetation zonation among the microhabitats of an artificial river channel: analysis and application of below-ground species trait patterns. Ecological Engineering, Oxford, v. 18, n. 2, p. 135-146, 2001.

MAMEDE, M. C. H. Byrsonima. In: REFLORA: lista de espécies da flora do Brasil. Rio de Janeiro: Instituto de Pesquisa Jardim Botânico do Rio de Janeiro, 2013. Disponível em: <http://floradobrasil.jbrj. gov.br/2010/FB008827>. Acesso em: 12 Jul. 2011.

MARCOS FILHO, J. Fisiologia de sementes de plantas cultivadas. Piracicaba: FEALQ, 2005. 495 p.

NAKAGAWA, J. Testes de vigor baseado no desempenho das plântulas. In: KRZYZANOWSKI, F. C.; VIEIRA, R. D.; FRANÇA NETO, J. B. (Ed.). Vigor de sementes: conceitos e testes. Londrina: ABRATES, 1999. p. 1-24.
RÉU JÚNIOR, W. F. Interações formigas-Malpighiaceae, Byrsonima intermedia (A. Juss.) e Heteropterys pteropetala (H.B.K.) no cerrado: atratividade ligada aos nectários extraflorais e defesa biológica à planta. 2005. 230 f. Tese (Doutorado em Ciências) - Universidade de São Paulo, Ribeirão Preto.

RODRIGUES, R. R.; SHEPHERD, G. J. Fatores condicionantes da vegetação ciliar. In: RODRIGUES, R. R.; LEITÃO-FILHO, H. F. (Ed.). Matas ciliares: conservação e recuperação. São Paulo: EDUSP/FAPESP, 2000. p. 101-108.

SIGRIST, M. R.; SAZIMA, M. Pollination and reproductive biology of twelve species of neotropical Malpighiaceae: Stigma morphology and its implications for the breeding systems. Annals of Botany, London, v. 94, p. 33-41, 2004.

VILAS-BOAS, J. C. Fenologia e biologia reprodutiva de Byrsonima intermedia A. Juss. e B. pachyphylla Griseb (Malpighiaceae): recursos-chave em remanescente de cerrado, Mato Grosso do Sul, Brasil. 2009. 43 f. Dissertação (Mestrado em Biologia Vegetal) - Universidade Federal do Mato Grosso do Sul, Campo Grande. 